\title{
Transition Thinking and Business Model Innovation-Towards a Transformative Business Model and New Role for the Reuse Centers of Limburg, Belgium
}

\author{
Leen Gorissen ${ }^{1, *}$, Karl Vrancken ${ }^{2,3}$ and Saskia Manshoven ${ }^{2}$ \\ 1 Transition Research Coordination Team, Flemish Institute for Technological Research (VITO), \\ Boeretang 200, 2400 Mol, Belgium \\ 2 Sustainable Materials, Flemish Institute for Technological Research (VITO), Boeretang 200, 2400 Mol, \\ Belgium; Karl.vrancken@vito.be (K.V.); Saskia.manshoven@vito.be (S.M.) \\ 3 Department of Bio-engineering, University of Antwerp, Groenenborgerlaan 171, 2020 Antwerp, Belgium \\ * Correspondence: leen.gorissen@vito.be; Tel.: +32-14-33-59-56
}

Academic Editor: Giuseppe Ioppolo

Received: 3 November 2015; Accepted: 15 January 2016; Published: 26 January 2016

\begin{abstract}
The current dynamics of change, including climate change, resource depletion, energy transition, internet of things, etc. will have substantial impacts on the functioning of contemporary business models. Most firms and companies, however, still largely focus on efficiency strategies leading to sub-optimal solutions (reducing bad impact), rather than radically changing their business model to develop new transaction models more appropriate for today's world (doing better things). However, persistent sustainability issues arising from our changing societal systems, require more radical and structural changes both within and between organizations to change the way we do business. There is limited empirically established research literature on how businesses can be more proactive in this regard and how they can move beyond "management of unsustainability". In this paper, we present a transformative business model innovation approach inspired by transition theory combining elements of systems thinking, value-inspired envisioning, reflexive design and co-creation that was pioneered for a consortia of reuse centers in the province of Limburg, Belgium. We demonstrate that this approach contributed to the development of new business model concepts, was conducive for mobilizing support and resources to ensure follow up activity and holds potential to promote a more proactive role for businesses as agents of transformative change.
\end{abstract}

Keywords: business model innovation; transition; circular economy; process design; new business models

\section{Introduction}

In today's world, businesses have to deal with super-fast changes in the market and accelerating disruption [1]. They also have to face increased uncertainty and complexity fueled by, e.g., globalization, digitization and grand challenges such as resource depletion, climate change and increasing inequality. These dynamics are often referred to as the managerial abbreviation VUCA (Volatility, Uncertainty, Complexity and Ambiguity) [2]. Business model innovation as-usual approaches do not take into consideration these dynamics and are thus no longer appropriate to deal with such meta-level pressures and micro-level disruption. To deal with VUCA dynamics effectively, more transformative thinking and organizing is required, triggering a significant transformation in the way doing business is arranged and organized [3]. This requires a mode of explorative business model innovation focusing on increasing reflexive capacity, mobilizing networks and "learning while 
you go" to explore future roles, collaborations and new organizational arrangements. There is limited empirically established research literature on how sustainability can guide business model innovation for wider transformation of the entire industrial system (see for instance [4-6]). Current innovation trajectories predominantly aim at optimizing business-as-usual practices thereby perpetuating the status-quo [7], which we define as eco-efficiency discourses. The magnitude of the grand challenges, however, require system innovation, changing the logic of value creation and shaping new transaction models more appropriate for today's world $[3,8]$.

In other words, to get out of the "management of unsustainability" lock-in, systemic transformations or transitions towards sustainable configurations will be required $[9,10]$ to effectively shift from "doing things better" to "doing better things". In that logic, expanding business model innovation approaches to include transition thinking might stimulate innovative thinking beyond eco-efficiency and promote repurposing to favor more appropriate and sustainable transaction schemes. While the business model concept is a recent and popular metaphor for explaining how companies create, deliver and capture value [11], the link to the wider impact in terms of sustainability is often neglected. What is more, traditional business model research predominantly concentrates on the generation and delivery of economic value and value for the customer [12] thereby reinforcing incumbent neo-liberal paradigms. Sustainability oriented business model literature on the other hand builds on the notion that value should be understood in broader terms by incorporating a triple bottom line approach and combining a systems and a firm-level perspective (e.g., [4,12]).

While still underexplored, a few recent publications have investigated the intersections between sustainability and business model thinking (e.g., $[8,13,14])$. Bocken and colleagues describe eight sustainable business model archetypes as exemplars to assist the innovation process for embedding sustainability in business models [8]. These are: (1) maximize material and energy efficiency; (2) create value from "waste"; (3) substitute with renewables and natural processes; (4) deliver functionality rather than ownership; (5) adopt a stewardship role; (6) encourage sufficiency; (7) re-purpose the business for society/environment; and (8) develop scale-up solutions. While the authors point out that each can be applied in isolation, they also highlight that real sustainability almost certainly demands combinations of archetypes (e.g., deliver functionality rather than ownership, while maximizing material and energy efficiency). In addition, Boons and Lüdeke-Freund point out that developing business models for sustainable innovation is mostly about a process that involves inter-organizational networks and even wider societal systems [15]. Such networks do not only include firms, but also other stakeholders. Furthermore, system innovation requires mutual reinforcing dynamics between entrepreneurial businesses promoting transformative ways of value creation and regime players with the power to overcome important barriers such as business rules, behavioral norms and success metrics [16-19]. More systemic oriented innovations are expected to have a greater sustainability potential (e.g., [20,21]), however, current business model research still predominantly focuses on business model innovation within one or a few companies instead of focusing on the wider ecosystem of state, market, civil society and science.

The purpose of this paper is therefore to describe a process of business model innovation as unusual. We describe a transformative business model innovation approach in which actors from the wider ecosystem have been involved in a setting of co-creation and co-evaluation. We contribute to the literature in three ways. First, we designed a business model innovation process that links the company perspective to the wider governance approach of transitioning to a circular economy, involving a multitude of stakeholders. Second, we adopted a system innovation perspective inspired by transition thinking to better understand the dynamics of change and to identify new roles and transaction arrangements with the aim to promote strategic agency between niche and regime players. Third, we showcase an exemplar of how action research can support the development of business models with increased sustainability, which might be of inspiration for the further development of a transformative research agenda. The applied business model innovation approach combines elements of systems thinking (multilevel approach), envisioning (value-inspired vision), reflexive 
design (questioning traditional structures) and co-creation (shared and collective value creation) that we developed and pioneered for a consortia of five reuse centers (locally branded as 'Kringwinkel') in the province of Limburg, Belgium.

Our case demonstrates that this approach contributed to the development of new business model concepts, was conducive for mobilizing people and resources to ensure follow up activity and holds potential to inspire new paradigms altering the current divide between the social and regular economy. We argue that this approach can be instrumental for the wider business community since it illustrates how companies can organize a process of shared and collective value creation and how they can set into motion a dynamic for the further development of new roles, new organizational arrangements and new collaborations to increase resilience in response to transformative times. The description of this case should be viewed as a small and modest attempt to link business model innovation to wider system innovation and how the research community can take on a more pro-active role in such innovation trajectories to inspire and promote increased levels of sustainability.

\section{Methodology}

\subsection{The Social Enterprise and Its Future Role}

In Belgium, product reuse is largely organized by the reuse centers, non-profit social enterprises that collect and repair donated goods (e.g., furniture, equipment, toys, clothes, etc.) for resale as second hand goods in a chain of local "reuse shops" [22]. By offering employment for unskilled personnel and providing quality goods at low prices for low-income households, the reuse centers play an important role in the local social economy. However, recent reorientations on the national and international level impact the playing field and working conditions of the reuse centers. On the one hand, austerity measures adopted by the government decrease subsidies for the reuse centers, while on the other hand, changing paradigms such as cradle2cradle (waste free design method) and eco-cycology (companies that take back and recycle all their goods) can alter the existing value chains and networks. Additionally, the interests of the growing recycling industry can cause potential tensions between "reuse of products" and "recycling of materials". In this regard, the recent concept of a "circular economy" prioritizes reuse, repair and remanufacturing of products and components over mere material recycling, as these activities preserve inherent product value and yield more environmental benefits in comparison with recycling. For example, used clothing can be resold as secondhand clothing or can be frayed into fibers and reprocessed into new products such as carpets, insulation, etc. These changing dynamics at macro and micro scale put pressure on the current business model of the reuse centers, which is based on the reselling of voluntarily donated reusable goods in local shops by employing socially disadvantaged personnel. Triggered by these changing circumstances, the directors of all five reuse centers of the province of Limburg (Belgium), which represented 16 local reuse shops in total at the time, induced a joint project to better respond to these changing societal dynamics, while creating additional added value for their local communities [22].

\subsection{Conceptual Background}

Scholars in transition theory explicitly address issues of sustainability in the dynamics of change and define a sustainability transition as a "radical transformation towards a sustainable society in response to a number of persistent problems confronting contemporary modern societies" [10]. This means that it brings about fundamental change in the ways of organizing (structures), ways of thinking (cultures) and ways of doing (practices). Transition scholars have developed a number of lenses to increase our understanding of transitions: the multilevel perspective, describing interactions between different scales; the multiphase perspective describing development through different phases; and the multi-pattern perspective describing how elements give rise to different patterns (Figures 1 and 2) [23]. From the business perspective, it is clear that sustainability issues cannot be addressed 
by single organizations but need more systemic approaches focusing on co-evolutionary changes in technology, culture, economy and organizational structures [24].

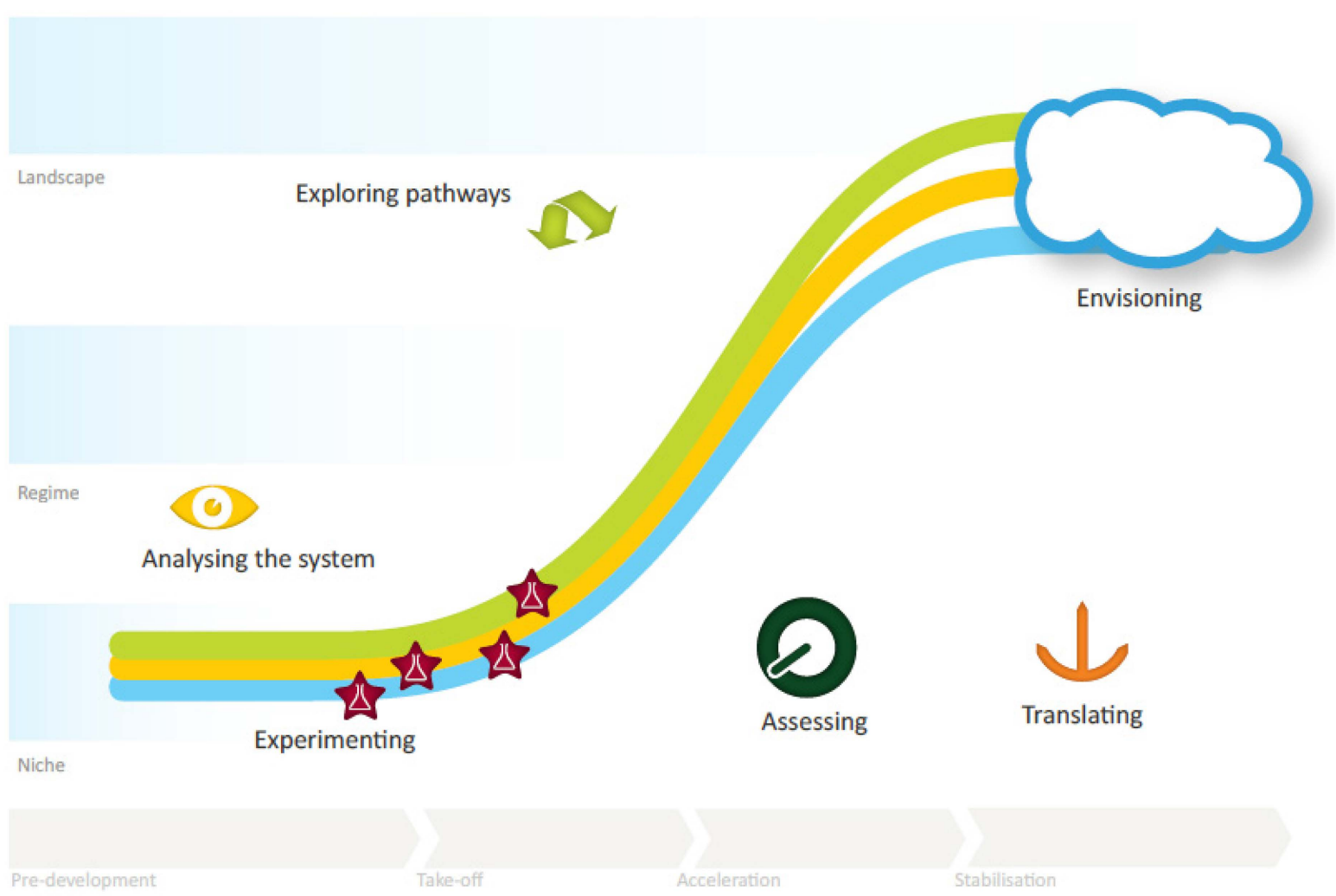

Figure 1. Transitions to sustainable development: A logical combination of reinforcing steps and associated activities [25].

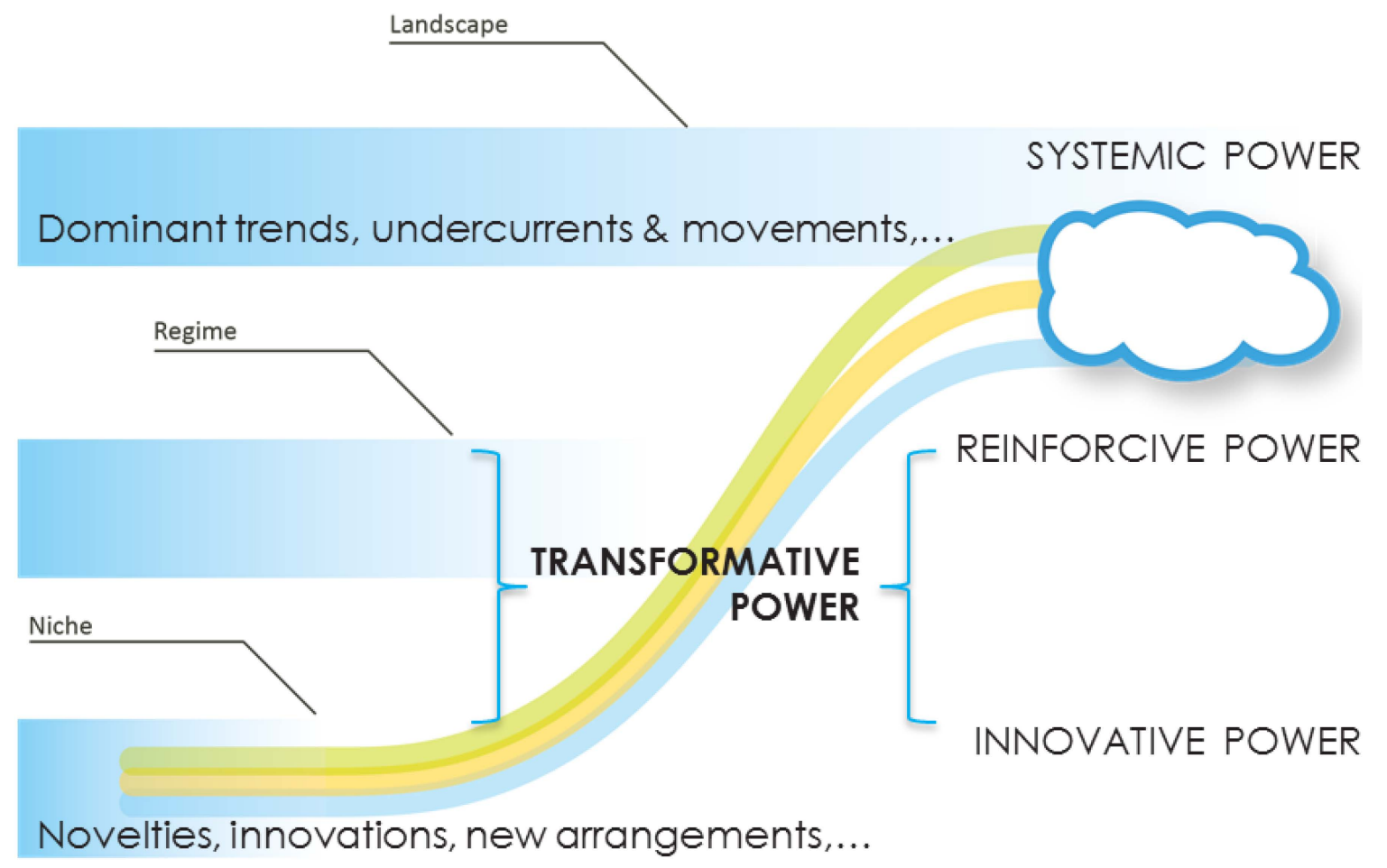

Figure 2. Multilevel perspective in relation to different types of power (reworked from [26]). 
According to [24], transition management (TM) takes a process approach that aims to change the dominant culture, structures and practices of unsustainable systems by connecting innovations at the micro-level to macro-level changes in mind-sets. To achieve such change, different roles and practices are required across the wide spectrum of involved actors: scientific institutes, companies, governmental bodies, NGOs, etc. These new activities and roles can be conceptualized from a governance perspective into strategic, tactical and operational transition management [27]. In other words, a TM approach helps to analyse co-evolutionary processes of social transformation and aims to develop strategies to influence and accelerate such processes [24].

In doing so, it includes a combination of mutually reinforcing steps and associated activities [25], as presented in Figure 1. These steps intend to:

- Understand how the current systems functions, what does and what does not work, what is appropriate and what is not (analyzing the system).

- Imagine how we would like the future system to look like and function, what is desirable, what is sustainable (envisioning).

- Explore how we can evolve from the current situation to the envisioned system and what trend breaks are required (exploring pathways).

- Explore how the chosen pathways can be translated into practical actions and how the trend breaks can be induced (experimenting).

- Monitor the transition process through follow-up and reflection on all actions, events, policies and strategies that influence the transition in question; and hence feed a process of social learning, which is a prerequisite for eventual success (assessing).

- Translate the lessons learnt into change-inducing actions in order to incrementally transform ("transitionize") the system, closer to a dynamic sustainable equilibrium (translating).

These elements should be considered as an indicative and guiding framework rather than a chronological sequence or ready-to-use toolbox [25]. In essence, transitions are seen as learning trajectories where the actual outcome/design has a high degree of emergence and is highly determined by the people that are involved in the process.

TM processes are generally guided by a "transition-team" that co-designs the process and feeds in relevant information to the local transition "arena". The arena is considered as an initial incubator of visionary change to inspire and initiate systemic transformation [26]. A transition arena has been described as an informal network of frontrunners (visionary people with abilities to think out-of-the-box and beyond current vested interests) within which a group process unfolds, often in an unplanned and unforeseen way [28,29]. Ideally, the arena is well balanced in terms of innovative niche players and change-inclined, entrepreneurial regime players. The participatory process is organized in a way that it stimulates systemic thinking, a shared language, new networks and coalitions, shared breakthrough experiments to identify new system settings and barriers that need to be overcome and generate trust and confidence in a future that is more sustainable [23].

\subsubsection{A Process to Promote Strategic Agency}

Avelino and Rotmans state that a TM approach particularly focuses on the empowerment of niche-actors by creating "space" for innovative thinkers and entrepreneurs, by enabling them to attain the necessary resources, strategies, skills and willingness to exercise innovative power; and by connecting niche-actors to each other so that they can form a broader and stronger network, a "niche-regime" that can exercise transformative power [30]. In addition, niche-actors are linked to regime-actors that can exercise constitutive power to establish a new distribution of resources at a structural level and anchor the new roles and collaborations at the regime level [30]. TM approaches thus aim to develop a new discourse with higher ambition level, where a long term vision is coupled to short/midterm action by means of a reform agenda [23]. In the process design of the transformative business model innovation for the reuse centers, we aimed to promote innovative and transformative 
power by the adoption of an arena setting in which we brought together a mix of different actors who collectively might promote strategic agency. The transition team (i.e., research team) developed the process design in close cooperation with the directors. Agency is thought to be crucial for the governance of system innovations since it can contribute by deliberately responding to or anticipating changes, opening up new courses of conduct that contribute to transformation and connecting novel practices to structural change [10].

\subsubsection{A Process of Reflexive Design}

The objective of the transition research team was to initiate a new discourse that could give rise to a new future role and business strategy for the reuse centers in line with the dynamics of change and aligned to macro level visions and strategies about new systems. Simultaneously, the aim was to inspire the negotiations for a new management agreement with the local intermunicipal waste company (IMWC: Limburg.net) that needed to be consolidated by the end of 2013. The timing of these negotiations provided an excellent opportunity to open up space to revise the current business model of the reuse centers and anchor this into the new management agreement. To initiate the process of rethinking the business model, we combined two conceptual approaches to promote systemic and strategic thinking: the multilevel perspective from transition theory [10,31] and the business model canvas [11]. The multilevel perspective (see Figure 2) helps to structure the societal dynamics into "levels" that put pressure on the system [10,25]:

- At the landscape level "gradients of force" are in play: dominant trends and evolutions from which it is difficult to deviate and which are rigid in the sense that it is difficult to change them on an individual base (e.g., globalization, climate change, ageing populations, etc.). Nevertheless, these prevailing evolutions and trends exert external pressure on the systems in place.

- A "regime" refers to the dominant culture, structure and practice embodied in physical and immaterial infrastructures (e.g., roads, power grids, routines, actor-networks, regulations, government and policy, etc.). Regimes are the backbone of the stability of societal systems and have a characteristic rigidity that very often prevents innovations from altering the standing structures fundamentally.

- Niches are often little visible small scale segments in society. In such protected environments, novelties are created and tested. These novelties can be (combinations of) new technologies, new rules and legislation, new concepts, new organizational arrangements, etc. Niches contain incubators for transition experiments and proofs of concept of radical innovations.

The business model canvas (BMC) approach is an approach to visualize the elements of a business model - the value proposition, structure, customers and finance- and their interrelatedness and is used as a tool to innovate business models [11]. By placing the BMC in the multilevel perspective of transition theory, we aimed to broaden current business model thinking to deliberately adopt systems thinking of the dynamics of change and to include aspects of (un)sustainability, since these will affect the success of the business model in the future. The combination of both approaches is presented in Figure 3. This approach was used to stimulate reflectivity and reflexivity about the dynamics of change. Reflexivity goes further than reflectivity because it also includes critically scrutinizing existing structures and institutions which are often not questioned in more traditional non-reflexive planning approaches [10]. This exercise formed the basis for the next steps of envisioning and identifying new business model concepts. 


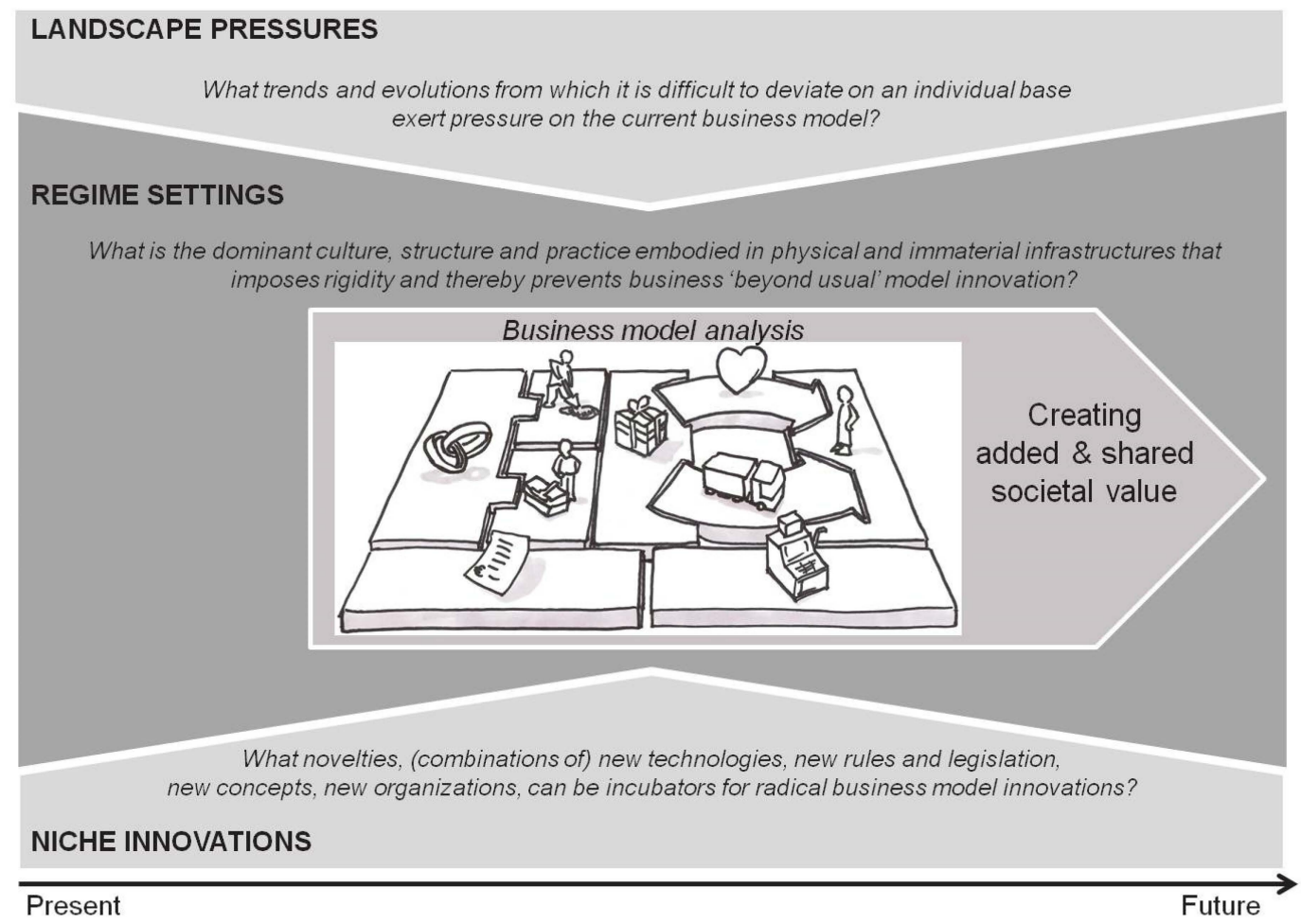

Figure 3. Business model exploration in relation to aspects of (un)sustainable development: a combination of a business model canvas approach and the multilevel perspective of transition theory [22].

\subsubsection{A Co-Creative Endeavor}

Our transformative business model innovation approach was specifically designed to facilitate multi-actor co-creation processes. Four distinct phases have unrolled since the start of the project (Table 1). In phase Ia and $b$, the directors of the five participating reuse centers were brought together for internal reflection sessions to understand differences in interests, activities and strategies amongst them and to align future ambitions and strategies (internal group trajectory). At the same time, an external trajectory in the form of a transition arena was set up, where the five directors were accompanied by ten local frontrunners, reflecting a wide spectrum of the society (public, private and social economy). The participants in the transition arena were selected in consultation with the internal group of directors. The group consisted of change inclined individuals from the regime (e.g., local IMWC, Limburg Governmental Administration, Public Waste Agency of Flanders) and entrepreneurs and individuals from the niche (e.g., SMEs active in sustainable development, the local Innovation Centre, someone from the target group of the social economy, a deliberative body on the social economy). They did not participate as representatives of their firm/organization but brought their expertise and experience into the arena based upon personal engagement. In between the arena workshops, internal feedback meetings with the five directors were organized to discuss the approach and the results from these participatory settings.

In phase Ia, the future role of reuse centers was explored and possible transition pathways in the form of new business model concepts towards this envisioned future state were identified (steps 1-6). Preceding phone interviews with the five directors and several stakeholders formed the basis to tailor the transition approach to the local context and gave important insights about the different views, perceptions and innovation inclination of the different actors. During the process, several internal group meetings and external arena workshops were organized, aiming at specific deliverables (Table 1). In such settings, the actors set out to jointly learn about the system, create a shared language, exchange 
viewpoints and perceptions and explore new business model concepts, roles and coalitions. Therefore, deliverables had to be achieved on the content, the process and the individual level in the arena workshops [see detailed description in 5]. In phase $\mathrm{Ib}$, strategies were considered to anchor the new future role in the regime setting via a new management agreement (steps 7-8).

Table 1. Overview of the phases and steps in the business model innovation trajectory. The order of numbers represents the sequence of the steps taken.

\begin{tabular}{|c|c|}
\hline \multicolumn{2}{|l|}{ PHASE Ia: Envisioning and Transition pathways } \\
\hline Internal group of 5 directors & Transition arena \\
\hline $\begin{array}{l}\text { Meetings (ranged from } 3 \text { to } 8 \text { h): } \\
\text { - } 1 \text { ) Business Canvas exercise } \\
\text { To review the current business model (strengths, } \\
\text { weaknesses) and envision a potential future role } \\
\text { (risks and opportunities) as a preparation for the } \\
\text { system analysis } \\
\text { (5) Synthesizing of results and feedback on } \\
\text { arena results and transition approach } \\
\text { To stimulate an internal dialogue and prepare a } \\
\text { concept note for the new management agreement } \\
\text { and an internal engagement declaration to formalize } \\
\text { the shared strategy; to synthesize the new vision and } \\
\text { strategy in an attractive brochure for communication } \\
\text { (6) Concept note and engagement declaration } \\
\text { To further discuss different views and } \\
\text { perspectives; to finalize the concept note and sign the } \\
\text { engagement declaration }\end{array}$ & $\begin{array}{l}\text { Workshops (ranged from } 3.5 \text { to } 4 \text { h): } \\
\text { - (2) Arena 1: System analysis } \\
\text { To explore the system (actors and factors): } \\
\text { (1) what are the dominant landscape trends and } \\
\text { evolutions from which it is difficult to deviate, or } \\
\text { which are difficult to change on an individual basis } \\
\text { (e.g., globalization, climate change, ageing } \\
\text { populations etc,) that potentially impact the business } \\
\text { model and (2) which niche innovations or novelties } \\
\text { can change the playing field in the future (e.g., new } \\
\text { technologies, new rules and legislation, new } \\
\text { concepts, new organizations); to learn about } \\
\text { perceptions of threats and opportunities } \\
\text { (3) Arena 2: Envisioning } \\
\text { To reflect upon values and principles; to } \\
\text { develop a narrative on a desirable future state that } \\
\text { can give direction to short/medium term action } \\
\text { (4) Arena 3: Transition pathways } \\
\text { To translate the vision into future-oriented } \\
\text { plans; to identify trend breaks/shifts that are } \\
\text { required to realize the vision; to identify } \\
\text { breakthrough experiments in function of the required } \\
\text { shifts/realization of the new roles }\end{array}$ \\
\hline \multicolumn{2}{|l|}{ PHASE Ib: Anchoring } \\
\hline \multicolumn{2}{|l|}{ Internal group of 5 directors + IMWC } \\
\hline $\begin{array}{l}\text { Meetings: } \\
\text { - (7) Exchanging visions } \\
\text { To exchange the vision of the reuse centers and } \\
\text { synergy and points of divergence; to stimulate anchor } \\
\text { - } 8 \text { ) Towards a new management agreement betw } \\
\text { waste company } \\
\text { To discuss how a new role for the reuse centers } \\
\text { to discuss mutual transition experiments }\end{array}$ & $\begin{array}{l}\text { the intermunicipal waste company; to identify points of } \\
\text { ge of the new vision in the regime } \\
\text { en the reuse centers and the intermunicipal } \\
\text { a be translated into the new management agreement; }\end{array}$ \\
\hline
\end{tabular}


Table 1. Cont.

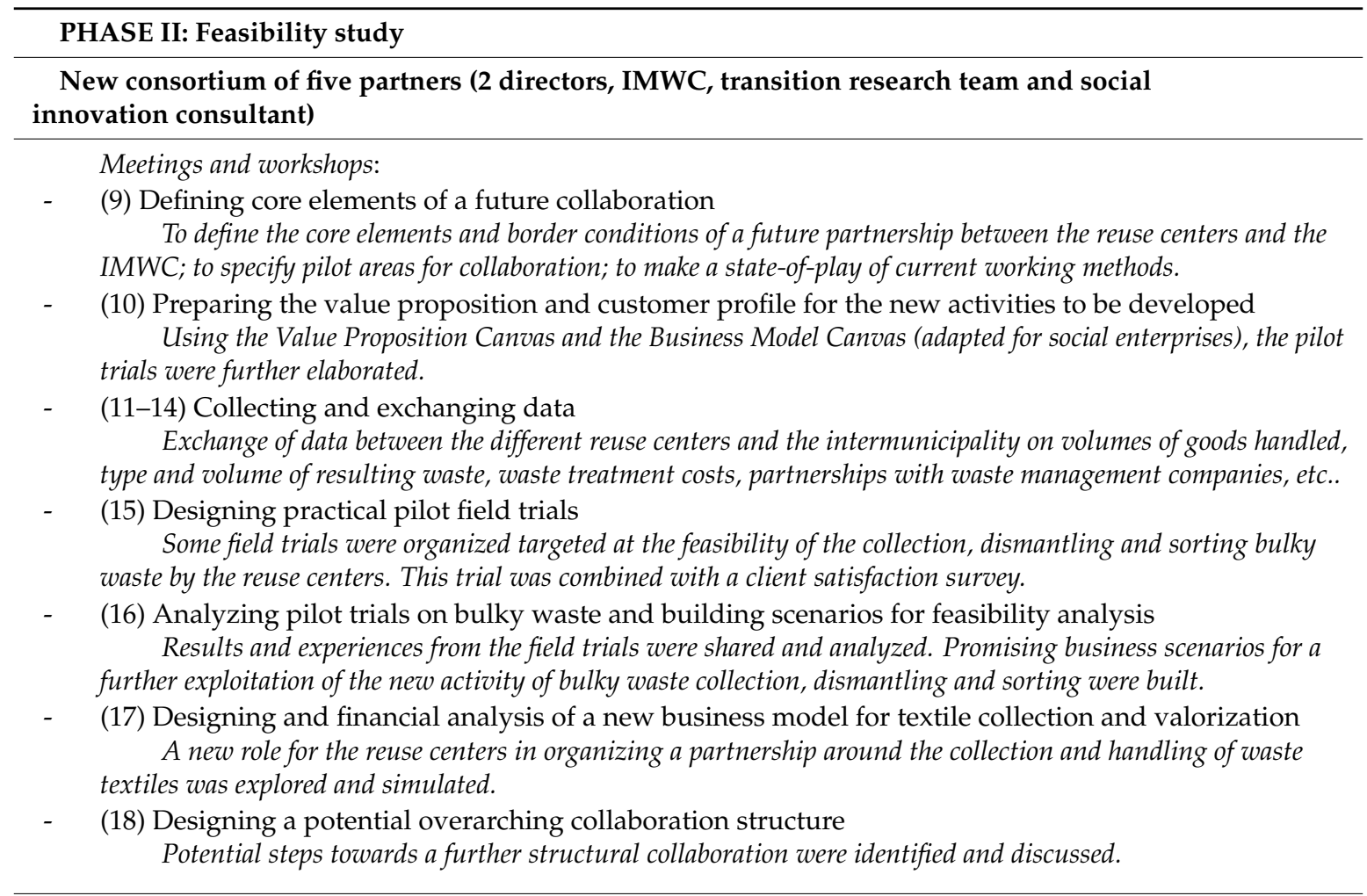

PHASE III: Towards a mandate for transformative action

Three reuse centers and their company boards

Meetings:

- (19) Validating the vision and presenting findings from the feasibility study

To present the co-created vision towards their company boards and obtain endorsement for this shared vision; to get a third reuse center back on board; to achieve a mandate for transformative change of their business model

PHASE IV: Towards an in-between organizational mode?

Three reuse centers and their company boards (communication with 2 other reuse centers)

In progress:

- $\quad$ (20) Next steps

To discuss with the board directors the next steps and how to develop the further steps in the process

In Phase II, a new consortium was established that explored the feasibility of the identified new concept of the "material match maker". The consortium was composed of two directors of the reuse centers, the IMWC, a research partner and a social innovation consultant. In this feasibility study for which they had acquired external funding, they set out to draw the outline of a new overarching organizational structure that can unite the reuse centers, as well as potentially interested social economy partners and private companies in a collaborative partnership. The aim of this partnership was to join future initiatives in the field of material cycle closure, reuse and valorization of waste and to facilitate the development of new ventures. Through a series of internal workshops, three specific pilot trials for new services, new co-operation modes and new financing schemes were explored.

In Phase III, the vision and feasibility study was presented to the company boards of three reuse centers. The aim here was threefold: (1) to validate the vision with their boards to increase legitimacy and support; (2) to get a third reuse center back on board; and (3) to obtain a mandate for further transformative change of their business model from their boards (including the required resources 
needed for the further process). Phase IV is in preparation and includes streamlining of organizational arrangements for which the first steps are being taken at the moment of writing.

\section{Results}

\subsection{Investigating the Regime Context}

To inspire the business model innovation trajectory, the research team developed a background study, investigating the wider context that is relevant for the work of the reuse centers. What is important in terms of the current regime is the fact that Flanders can be regarded as a frontrunner when it comes to sustainable resource management. The most apparent example is the shift from a Flemish waste regime into a sustainable materials regime leading to new legislation (Materials Decree) in 2011, which goes several steps further than the EU requirements and which was initiated by the transition platform "Plan C" that started in 2006. "Plan C" was introduced by the Public Waste Agency of Flanders (OVAM) originally to develop a long term policy orientation for the waste system but it shifted the discourse from waste management to sustainable resource management in which the waste system is regarded as part of a "higher" system: the material system [32].

The new discourse was anchored through the approval of a Flemish Materials Programme in 2012 [33] and gave rise to the Policy Research Centre sustainable materials management (SuMMa). These transformations will have a large impact on the institution of intermunicipal waste companies with whom the reuse centers have management agreements authorizing what kind of activity they can unfold and the ways in which their work is subsidized. This new discourse on the regime level will thus affect the playing field of reuse centers and their "kringwinkel" shops. In addition, developments on a EU level regarding the concept of a "circular economy" enforce the Flemish shift to materials management. This background analysis allowed us to partially "reframe" the current project to better align to the new policy discourses and long-term vision for resource management at higher governance levels.

\subsection{Phase I: Envisioning and Transition pathways}

Results are described in the order of the steps taken (see Table 1). Results of Phase I are described in detail in [22]. We will recapitulate the main findings since these are necessary to understand the results of Phases II and III that further build upon these.

\section{(1) The business canvas exercise}

The internal trajectory was kicked off in 2012 by an internal group session in which the five directors individually outlined their personal vision on a desirable future for their respective reuse centers. Afterwards, they reflected on the different elements of their business model and which parts were perceived to be under pressure given the current societal trends and innovations. This systems analysis was instrumental for a SWOT assessment on perceived threats and opportunities and helped to increase reflexivity. The internal envisioning exercise and the preceding individual interviews revealed a wide diversity in perceived sense of urgency and ambition level across the five directors, which we interpreted as differences in innovation inclination between the directors. In order to enrich the results of this internal envisioning, a similar exercise was repeated in the first arena session where the internal group was complemented by 10 external frontrunners.

\section{(2) Arena 1: From BM canvas to BM in the wider dynamics of change}

During the first arena session, the participants considered the business model of the reuse centers from a systemic perspective and shared their perceptions on factors influencing the current business model. This exercise provided insight into the complexity of the system wherein the reuse centers operate, which can be translated into a diversity of challenges that they have to overcome and opportunities that can be seized. The biggest challenges (or threats) that were identified are: (1) the 
dependency of the reuse centers on governmental subsidies, which makes them vulnerable to political and policy changes; (2) the increasing competition for key resources (e.g., waste often gets stolen before collection); (3) the organization of reuse/recycling activities by the companies themselves inducing closed product/material loops (eco-cycology); and (4) the decreasing quality of the goods. The main opportunities were identified as: (1) the provision of meaningful work for disadvantaged people that empower them to make an acknowledged contribution to a low carbon society; (2) a shift from being subsidized to being compensated for the environmental and social services they provide to society; and (3) being a catalyst of innovation.

\section{(3) Arena 2: From "as is" to "to be"}

The second arena gathering was designed according to a solution focus entry point. This means that we set the stage building on the assumption that there are no barriers, no opposition and no hurdles ("everything that you undertake in the future, will succeed"). In this atmosphere, we asked the participants to co-develop a desired future state of the reuse centers. From these narratives, the fundamental values and mottos that underpin the vision were discussed, identified and consolidated and later integrated in a uniform vision text (Box 1). To fuel further dialogue, three arena participants from the current regime setting outlined their personal vision on the future of the social economy (participant 1), the future of the reuse/recycling policy (participant 2) and the future business of waste treatment, recycling and reuse (participant 3). The first opinions on what pathways are perceived to be possible/desirable or impossible/undesirable were also exchanged. Noteworthy is the fact that several participants indicated that they found the exercise of envisioning difficult because they are accustomed to think within the current system settings (e.g., state of practice of today) and from a "problem" stance.

\section{(4) Arena 3: From vision to practice}

The third participatory arena session focused on how the vision can be put into reality. The participants reflected on possible transition pathways to bring into practice the values, principles and mottos of the vision while adhering to the dynamics of change. Subsequently, they reflected on what kind of short term experiments might be helpful to learn more about these pathways. The different modes of thought converged into two possible pathways for the future: becoming a "material matchmaker" or a "service matchmaker" (see Box 1 for explanation). These pathways can be considered as two possible new business model concepts which allow the reuse centers to bring their activities more in line with the emerging concept of a circular economy, e.g., adhering to trends of product sharing, product-service systems and material cycle closure. In accordance with these new business model concepts, first ideas for pilot projects to be initiated in the short term were developed. One of the pilot ideas was the "all-round collector". In contrast to the present situation, in which each citizen has to sort his or her spent goods into "goods for reuse" versus "waste" and contact two different organizations to collect these; e.g., the reuse centers for the first category and the IMWC for the latter category, an all-round collector would collect all disposed goods of citizens and sort afterwards. This saves time and worries for the citizens and can potentially increase the amount of goods for reuse since a large part of the seemingly broken, damaged or unwanted goods can be repaired or upcycled into new products or dismantled into useful parts.

\section{(5) The synthesis workshop}

In a next step, the results of the arena session were discussed with the internal group of directors in a one day synthesis workshop in which the shared long-term vision was formally corroborated (Box 1). Next to discussing the outcomes of the arena session, the group was presented with insights of transition theory, for instance on power dynamics and the advantages/disadvantages of becoming a frontrunner, to further stimulate reflectivity and reflexivity. In these dialogues, differences in innovation inclination and "sense of urgency" among the five directors led to different viewpoints on 
that many of the values of the co-created vision had been replicated into the vision of the IMWC also suggests that co-creation can induce "ownership" in arena participants and stimulate anchorage of new values in the regime. Even though the visions of both the reuse centers and the IMWC were very alike, there was a difference in interpretation of the roles of the partners. The discussions afterwards allowed identification of the points of synergy and points of divergence.

(8) Towards a new management agreement between the reuse centers and the intermunicipal waste company

Next, the five directors of the reuse centers entered a negotiation phase with the IMWC to co-develop a new management agreement. In this process, the transition team took part as observer. The IMWC was open to revise the management agreement in support of the identified new business model concepts via:

» Anchorage of a changed logic of value creation, i.e., shifting from being subsidized to being rewarded for the societal and environmental services by means of a reorientation of the current financial model. This would allow the reuse centers to employ more personnel and increase their environmental services which is not possible in the old subsidy model.

$\gg \quad$ Exploring new organizational arrangements between the reuse centers and the IMWC.

$\gg$ Inserting an addendum to the management agreement providing space for joint experiments focusing on: (1) new ways to deal with resources/new resource distribution options that favor more effective product reuse or upcycling; and (2) new roles for reuse centers that can be developed.

Off course, revising the management agreement also increases uncertainty since old arrangements such as the subsidy deal would then come to pass. In addition, shifting from being subsidized to being rewarded for the societal and environmental services also increases the need for transparent accounting. This became a bottleneck for two of the reuse centers who preferred to go back to the old routine. Because of this, the negotiations ended and the revisions mentioned above were not included into the new management agreement.

However, the two most changed inclined directors (frontrunners) together with the IMWC agreed to collaborate on a joint follow up study to investigate the new business model concept "material match-maker" further in terms of feasibility. An interesting example of dispersion of the ideas out of the arena setting is the fact that the policy group of the i-Cleantech Flanders Platform-with amongst others, representatives of the Ministry of Innovation-picked up the ideas of material matchmaker and service matchmaker and shortlisted these ideas as possible topics to fund [35]. This result shows that the arena setting was indeed favorable for strategic networking. The new consortium of the IMWC and two reuse centers applied to this fund and succeeded in getting half of their feasibility study funded. Hence, the focus on supporting strategic agency resulted in both the dispersion of ideas, the formation of new collaborations and mobilization of new resources for follow up activities.

\subsection{PHASE II: Feasibility study}

(9) Defining core elements of a future collaboration

In January 2015, the first workshop of Phase II was organized in order to define the core elements and boundaries of a future partnership between the reuse centers and the IMWC. The aim of such a partnership is to improve their service to clients (citizens and companies) by organizing material and waste related services in a more simple and transparent way. Additionally, the societal and competitive position of reuse centers would be strengthened by clearly defining and claiming their role in the pursuit of a circular economy via the business model concept "Material Matchmaker" (Figure 4). The key elements of the desired overarching collaboration structure were identified as [36]: 
» close collaboration between all reuse centers in the province of Limburg, in order to be able to act as one negotiation partner with the IMWC Limburg.net and to guarantee a uniform way of working within the whole province;

» win-win collaboration with social economy players as well as private partners, no competition;

» objective of the reuse centers remains focused on the creation of employment for disadvantaged people;

» initiatives must be financially viable and create added value for society;

$\gg$ transparency and openness in financial and other data; and

$\gg$ clear agreements on ownership of waste fractions (and their associated costs or revenues).

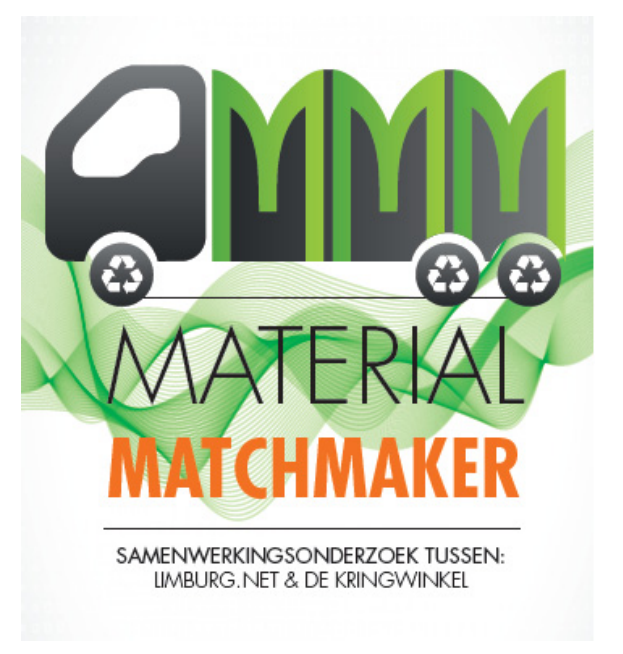

Figure 4. Exploring the feasibility of the business model concept "Material Matchmaker".

Three specific themes for further experimenting and exploring were identified, being: (1) "dismantling and material valorization of non-reusable goods"; (2) "bulky waste collection"; and (3) "textile collection and handling" [21].

(10) Preparing the value proposition and customer profile for the new activities to be developed

Using the Value Proposition Canvas and the Business Model Canvas (adapted for social enterprises), the new activities identified for trial were further elaborated. Key questions to be answered were:

What is the value proposition of the service? What need is being addressed?

$\gg$ Who is the targeted customer?

$\gg$ Who are potential partners?

$\gg \quad$ Who are our competitors? Can we turn them into partners?

$\gg$ What are associated costs/revenues?

» How can we design the service to best serve the client?

\section{(11-14) Collecting and exchanging data}

During several workshops data and ideas for collaboration modalities were exchanged, checked within the individual organizations and reworked. This process took considerable time (five months), as the designing process was hindered by several difficult issues resulting from the predominant regime, e.g., existing agreements with third parties (such as waste treatment companies, waste collectors and incineration plants), political choices and sensitivities, financial issues, regulatory constraints, practical drawbacks, etc. 
(15) Designing practical pilot field trials

A three-phased field trial was designed in order to explore the feasibility of bulky waste collection and material dismantling by the reuse centers. The aims of the different phases were the following:

$\gg$ Estimate the effect of a less rigid policy in reuseable goods collection: no longer refusing goods that are not reuseable eases the relationship between the goods collectors on the field and the clients, which might lower the barrier for clients to make use of the collection service by the reuse centers and can possible increase the intake of reuseable goods. Clients are often not aware of which goods are reuseable and which are not, which can lead to discussions in the field.

» Gaining experience with the service of bulky waste collection: to explore the practical feasibility of the work and gain some experience with the aspects it comprises, including an estimation of the additional volume of re-usable goods that can be collected through this route.

$\gg$ Gaining experience with dismantling and sorting of non-reuseable items: how much time does it take (cost estimation), what competences are needed, what type of materials can be produced and what revenues can be expected from this activity.

(16) Analyzing pilot trials on bulky waste and building scenarios for feasibility analysis

The results and experiences from the field trail were shared within the consortium. By actually bringing into practice the idea of the "all-round waste collector" via a trial several bottlenecks came to light: existing contracts with waste companies need to be changed, collection methods need to be revised, additional infrastructure will be needed, etc. In addition, the trial showed that the expected revenues from an increased volume of reuseable items appeared to be relatively low, compared with the increased costs for collection. In other words, the financial viability of this service proved to be more difficult than was expected. More fundamentally, changing from collecting reuseable goods towards collecting all goods, including bulky waste, would mean a shift of focus for the reuse centers and would require fundamental shifts in their practical operation (e.g., transporting reuseable things together with waste might pollute the reuseable goods). They would actually become real waste managers, which was considered to be too far away from their desired vision. The idea of bulky waste collection subsequently was abandoned after the trial [36].

(17) Designing and financial analysis of a new business model for textile collection and valorization

Here, a new role for the reuse centers in organizing a partnership with other actors in the collection and handling of waste textiles was explored and simulated. A "textile reuse center" concept was designed in which all reuse centers would participate, together with other actors. Some first ideas on the practical organization of such a center, additional sorting activities that could be taken up and the financial and physical flows were simulated in an exploratory business plan. The idea proved to be viable and will be further developed into a business plan with a specialized consultant.

\section{(18) Designing a potential overarching collaboration structure}

The general idea of the "Material Matchmaker" concept is the set-up of a collaboration or co-operation in which the current and future activities of the reuse centers can be united and aligned to the notion of a circular economy. The potential phases in the set-up of such a structure were defined, starting with a first collaboration on non-core activities in order to increase efficiency and reduce costs (e.g., jointly offering waste streams to the market, aimed at obtaining better prices and conditions through scale advantages and a stronger negotiating position). In further phases, the collaboration can be expanded towards other activities, such as the pooling of infrastructure, administrative burdens or even personnel. Different legal forms were explored as well. 


\subsection{PHASE III: Towards a Mandate for Transformative Action}

(19) Validating the vision and presenting findings from the feasibility study

In June 2015, a workshop was organized with three reuse centers and their company boards to present the work that had been done so far. First, the vision that had been co-created in the arena sessions was presented and discussed with the boards. Formal endorsement of this shared vision was achieved in all boards. The second objective of this workshop was to get a third reuse center back on board in the change process, which was also realized. The main objective however, was to receive support from the reuse centers' boards in the form of a mandate to go into a process of transformation of their current business model. This objective was also achieved: the boards expressed their support for this next step and they agreed that a new organizational arrangement across the different reuse centers is a basis for further action. They also emphasized that urgency and formal commitment are needed to go forward. The directors thus received a formal mandate for transformative action. They agreed to draw up a strategic note and discuss this in a next phase with the three board executives.

\subsection{PHASE IV: Towards an in-between Organizational Mode?}

\section{(20) Next steps}

Two weeks later, the strategic note was discussed between the directors and board executives of the three reuse centers. One representative of the research team was also present. The objective was to determine the next steps that will be taken. In the previous meeting, a structural collaboration between the three reuse centers had already been discussed. Given the fact that austerity measures in the government negatively impact available resources, the three board executives articulated that-to create formal commitment across the three reuse centers-the preferred strategy is to go into a merger. That way, the efficiency gains from aligning and streamlining activities can create space for the further enrolment of the business model transformation process. There is, however, an important tension that surfaces when going into a merger: one of the values of their co-created shared vision is the "deep grounding/embedment in the local communities".

How to still guarantee this proximity to the local communities the reuse centers service while shifting towards a provincial meta structure still remains to be determined. What is also relevant is the fact that they decided to open up the communication channels towards the two other reuse centers again as they aspire a collaboration between all reuse centers of the province of Limburg. Thus, at the moment of writing, the reuse centers and their boards are discussing internally how to proceed next and they see a merger as an important in-between state that can provide more space for the further transformation of their business model. Much will depend upon how this merger is going to be designed. Agility will be vital for the reuse centers to develop a new business model and this is often more difficult in large organizations compared to smaller ones.

\section{Discussion}

\subsection{Business Model Innovation as Unusual}

As a first step in this exploratory project, the directors of the reuse centers together with a selection of relevant (external) actors from diverse domains explored the values and underpinning mottos of the reuse centers' future (societal) role. The results of this exercise were translated into a vision of shared, multiple and collective value creation and formed the basis for the exploration of new business model concepts that fit in an envisioned future society that functions within the boundaries of significantly different material management principles (e.g., circular economy). In this process, two new business model concepts were identified as "material matchmaker" and "service matchmaker". To bring these two identified new business model concepts into practice will require new (in between) organizational formats concerning the social and regular economy and new transaction models which are bound 
to clash with current instruments and institutions developed from the linear (take, make, dispose) economy paradigm.

The transformative business innovation process that was designed set into motion a dynamic to explore such new organizational arrangements and changed logics of value creation. At the moment, the reuse centers are investigating whether a merger could be an in-between stage that could open up space for further investments in the transformation of their current business model. The case of the reuse centers offers a practice-based example of a much closer collaboration between science, the government, the market and civil society to co-determine new courses of (more systemic) change in sustainable resource management. It shows that businesses themselves can become catalysts in shaping new economic paradigms for increased sustainability and that science as a reflexive partner can support this process. The approach employed in this practice-based case can provide support and be inspirational for both the business and scientific world interested in repurposing and redesigning innovation trajectories towards higher levels of sustainability and resilience.

Especially in terms of innovative and transformative power [30], this case illustrates that including an agency and governance perspective [17] in the process design of business model innovation is beneficial in terms of mobilizing resources (both people and money) for transformative action. For instance, the identified new business model concepts "material and service matchmaker" dispersed into new and powerful networks such as i-Cleantech Flanders that included these topics on their short list of interesting ideas to fund to which a newly formed consortium of reuse centers, IMWC, social innovation consultant and research team could apply [35]. This secured resources for a follow up study to investigate the feasibility of new organizational arrangements between the reuse centers and the IMWC which are regarded as necessary stepping stones towards a new business model [37]. For instance, the field trial on becoming an "all-round collector" helped to identify important barriers ingrained in the current business rules that prevents the development of new organizational formats.

One of the most noteworthy advantages of the applied approach is that it set into motion a dynamic for transformative change promoting also reorientations of regime institutions, as is illustrated by the openness of the IMWC towards including new organizational formats, adopting a changing transaction logic and setting up transition experiments in the new management agreement with the reuse centers [22]. Furthermore, the approach helped to gain support from the Reuse centers' company boards who were positive about the change trajectory and the thorough study of feasibility [36,37], supported the vision and gave the directors a mandate for further development of new organizational arrangements to develop the new business model concepts further. Even though the described approach is no blue print, it will need to be tailored to the specific context of an organization and its governance context, the wider business community can draw inspiration from this case to assist them in embedding sustainability into their purpose and business model innovation process. Transition literature regards the following ingredients as fundamental:

$\gg \quad$ to adopt systemic thinking [25];

$\gg$ to develop a shared mental image "leitbild or vision" of an attainable, desirable and sustainable future underpinned by values and navigating principles [3,38];

$\gg \quad$ to germinate new actor/community networks and new collaborations [3,39];

$\gg \quad$ to select and orient short term innovation processes in line with the long term ambitions [23];

$\gg \quad$ to involve relevant governance actors open to transformative change to promote institutional innovation [32]; and

$\gg$ to stimulate explorations around transformations of current resource distribution and the marshaling of new resources [30].

That said, important opportunities for profound transformation have not been taken up further. One of the breakthrough insights in the arena trajectory-to shift from being subsidized to employ disadvantaged personnel to being rewarded for the positive social and environmental services-have not been implemented into the new management agreement with the IMWC, even though the latter 
was open to this. Such a shift would have significantly altered the rules of the game and could have been an important stepping stone in changing the logic of value creation that is needed to transform towards an inclusive and circular economy. In addition, current austerity measures from the Flemish government have negatively impacted the resources of the reuse centers thereby decreasing their innovation capacity to develop the new business models further. This has compelled the board executives that a merger between the reuse centers is needed as a first step towards the further enrolment of a new business model. Financially, this strategy makes sense, for the costs saved by unifying services such as HR, can then be invested in innovation. However, the practicalities and legal and administrative burdens might focus attention away from the long term. It will thus be quite a challenge to design a merging process where the development of a new business model is the ultimate goal.

In addition, the link to higher levels of governance, for instance to actors of the Flemish Waste Agency working on the topic of a circular economy or to actors working on social economic policy, watered down over time. These actors nevertheless play a crucial role when it comes to giving space for transformative experiments and overcoming barriers such as the ones encountered during the experiment of an "all-round collector". Grin states that active, creative agency can contribute to the governance of system innovation by promoting the co-evolution of mutually reinforcing novel practices from the niche and structural changes in the regime [17]. Additionally, to accelerate the transition to sustainability an accumulation of socio-cultural, economic, ecological and institutional changes is required [16]. Connecting the innovation trajectory of the reuse centers to change inclined actors from governmental institutions will thus be necessary to realize the required institutional innovation that is needed to open up new courses of conduct since new modes of value creation will require new rules.

\subsection{Action Research as a Catalyst for Shaping a Different Economic Platform}

Our findings are in line with the proposition of [40] that action research within organizations can develop leadership capabilities that are likely to enhance sustainability outcomes. What is more, by involving actors of all four pillars of the quadruple helix in a co-creative manner; i.e., science, civil society, government and market, the business innovation trajectory is not isolated from the dynamics in the wider socio-technical system [10]. This is in line with the findings of [9] who suggest that significantly better performance of the industrial system is possible without relying on the development of "step change" technologies but by investing in innovative thinking and careful planning. What is more, a quadruple helix approach promotes legitimacy (or fairness to a variety of actors) and salience (or relevance to decision making) of the business model innovation trajectory [41] and can promote faster diffusion of new paradigms in the wider industrial governance ecosystem.

In the presented case, scholars on sustainable materials management and on transition theory acted as a reflexive scientific partner with the clear intention to help the business partners innovate in an informed way. By using a broader frame of reference from the beginning (systems thinking and transition governance), the followed approach placed the process of business model innovation in the wider system of industrial change. Such an approach is deemed important to resolve the issues of unsustainability that our current industrial ecosystem faces. Only when we consider the whole system, we can access change on the scale that the grand challenges require $[8,9]$. We thus believe that by describing this case in detail, we contribute to the knowledge base of how multi-actor settings can jointly explore opportunities to develop new business models conducive for the transition towards a more sustainable industrial ecosystem.

Additionally, an effective contribution of science to sustainability transitions requires expanding the role of science. Next to answering research questions and providing the best science available, science at the service of society is becoming more relevant to resolve the persistent, unsustainable problems of our current economic system, suggesting that interdisciplinarity, transdisciplinarity and social relevance are the key elements of a science supporting sustainability transitions (see [42]). This also implies new roles for researchers such as change agent, knowledge broker, reflective 
scientist, self-reflexive scientist and process facilitator [42]. With this case, we illustrate how science can contribute to business model innovation processes in an informed way. Even though not all opportunities have been seized successfully, the enrolled business innovation approach can inform the wider business community since it provides a practical example of how to organize the process of shared and collective value creation and how to set into motion a dynamic for further development of new roles, new business models and new collaborations mobilizing both people and money. Furthermore, such exploratory research designs can help uncover important research questions such as how to better connect business model innovation to structural adaptations in governance, how to open up space for more transformative experiments, how to overcome risk adverse behavior and institutional inertia and how to transform innate but no longer appropriate business rules? In that way, cases like the one illustrated here can provide valuable insights concerning the implementation of sustainability in practice and can thus inform research innovation planning.

\subsection{Case Specific Lessons Learnt}

The current business model of the reuse centers of the province of Limburg is under pressure for multiple reasons. On a landscape level, these pressures include the economic crisis, the resource crisis and the digital revolution (with online sale outlets, etc.). On a niche level, these pressures include innovations geared towards new forms of ownership (sharing, leasing) and closing material cycles (e.g., cradle to cradle, eco-cycology). Recent transformations on the regime level in Flanders directly impact the playing field in which the reuse centers operate since these will have a large impact on the institution of intermunicipal waste companies with whom the reuse centers have management agreements authorizing what kind of activity they can unfold and the ways in which their work is subsidized. The new discourse shifting from waste to materials management on the regime level is thus very important for the future business model of the social enterprise "reuse centers" and their local shops.

By adopting a transformative business model innovation approach inspired by system thinking, transition theory and reflexive design, the co-creative process facilitated by the transition team was able to:

$\gg$ promote systemic thinking about the bigger picture, the factors, actors, trends and possible threats and opportunities affecting the current business model;

$\gg \quad$ align the business model innovation process with the ongoing dynamics on the regime level;

$\gg \quad$ induce a new discourse with a higher ambition level, fueled by an ambitious long term vision;

$\gg$ promote the development of new business model concepts (material matchmaker and the service matchmaker) that fit in an envisioned future society that functions within the boundaries of significantly different material management principles;

$\gg$ connect the long term vision to short term action through the follow up feasibility study that started in 2014 and the initiation of a new organizational mode;

$\gg$ promote institutional innovation by opening up opportunities to anchor the new roles and activities in the new business management agreement with the IMWC (impacting the wider governance setting) allowing experimentation and reorientation of the future role while at the same time offering stability in current practices. Unfortunately, this new management agreement failed because three reuse centers dropped their support in the final stage;

$\gg$ prompt diffusion of the new business model concepts into new innovative networks and governance midst;

» mobilize people and money for follow up activities and practice-based experiments;

$\gg$ raise support from the company boards for further investment in the business model transformation discourse;

$\gg$ prompt a dialogue on changing organizational arrangements and exploring new collaborations and roles; and 
» promote further reflection on how to proceed next; e.g., exploring a merger as an important in-between state that can provide more space for the further transformation of their business model.

Even though a careful process design is essential for obtaining results, not all goals have been achieved as the example of the failed new management agreement with the IMWC showed. The bottlenecks that prevented anchorage of a new logic of value creation and a new role for the reuse centers even though the regime partner IMWC was open to this, included the lack of: (1) a shared sense of urgency; (2) shared support for total transparency of all data; and (3) a lack of trust between certain partners. These factors induced three reuse centers to counteract the new management agreement at the last moment and step out of the change trajectory. However, even though this significantly delayed progress, it did not stop the innovation discourse since the two most change inclined reuse centers initiated a new collaborative effort with the IMWC and other partners to proceed with a follow up feasibility study. This feasibility study, co-funded by the influential i-Cleantech Innovation Platform, helped to get the third reuse center back on board by providing first quantitative estimations on possible added value of new organizational arrangements.

\subsection{Fueling Innovative and Transformative Power}

By including a focus on transition governance in the business model innovation process design, i.e., adopting strategies to empower frontrunners and develop and/or mobilize new networks, the applied approach promoted transformative power as well as innovative power $[30,43]$ which is congruent to the stakeholder theory from the business literature (e.g., [44,45]). Such impact is however not easy to measure and will only become obvious after a considerable period of time. Nevertheless, the take up of the ideas of material and service matchmaker by the policy group of the i-Cleantech Flanders with amongst others, representatives of the Ministry of Innovation clearly indicates that the ideas from the arena setting can quickly disperse into powerful networks. Therefore, the diffusion of the developed ideas and concepts into new platforms indicates that new ideas and business concepts arising from such small scale exercises can rapidly disperse from one to another governance level and can actually influence innovation agendas $[17,18,23]$.

Our findings are also consistent with the conclusion from transition management literature that much of the success depends on individual frontrunners that are committed to gradually work towards a novel business agenda [24]. This is also in line with the findings of [46] that social entrepreneurs play a role in spurring adoption of sustainability-oriented offerings in business environments and with [8] that further exploration of the role of business model innovation for sustainability in the social economy is needed. Even though the directors have gained the mandate from their boards to develop the new business model concepts further, the challenge to do so has only increased. Recent austerity measures have decreased their subsidies even further and the decision of the board executives to kick start the new organizational arrangement via a merger of the different reuse centers might focus attention and energy more to the short term.

\section{Conclusions}

In conclusion, the illustrated case shows that linking the company perspective on business model innovation to the wider governance and system innovation perspective was conducive for opening up space for experimentation and for enabling follow up activity. Furthermore, involving a multitude of stakeholders from multiple sectors in a process of co-creation resulted in the enfolding of strategic agency that successfully dispersed the ideas to powerful networks and mobilized both people and money for the further development of new business models. Whether this approach will effectively catalyze a significant transformation in the industrial system is, of course, dependent on the next steps. Nevertheless, we strongly believe that business model innovation in support of the transition to an inclusive and circular economy requires involvement of actors from all four pillars of governance. Even though this case is only a humble first small step, it does show that co-creative collaboration 
between science, business, state and civil society can support reflexivity and enable exploration of more transformative business models. It also shows that businesses can significantly support the transition to sustainability and can mobilize new means of innovation support even in times of economic downturn.

Acknowledgments: The initial project was supported by a grant from the Province of Limburg in Belgium, the feasibility study was funded by i-Cleantech Flanders and phase III was funded by reuse centers Kringwinkel West-Limburg VZW, Kringwinkel Okazie, Springplank vzw, De Container vzw. We are grateful for the time, interest and commitment of all the participants in the arena sessions and workshops. We would like to thank Stella Vanassche (VITO) and Sam Van Dyck (i-Propeller) for contributing to the feasibility study.

Author Contributions: The corresponding author was the lead in the conception, design, analysis and interpretation of Phase I, III and IV. S.M. was the lead researcher of phase II. K.V. contributed to the design of phase I and interpretation of the results of all phases. The corresponding author was the main responsible for drafting and revising the article. All authors contributed to the final approval of the version to be published of the paper.

Conflicts of Interest: The authors declare no conflict of interest.

\section{References}

1. Hinssen, P. The Network Always Wins; Mcgraw-Hill Education: New York, NY, USA, 2015.

2. Bennett, N.; Lemoine, G.J. What VUCA Really Means for You. Available online: https://hbr.org/2014/ 01/what-vuca-really-means-for-you (accessed on 19 January 2016).

3. Jonker, J. Nieuwe Business Modellen. Samen Werken Aan Waardecreatie. Stichting Our Common Future 2.0; Doetinchem \& Jan Jonker. Stichting OCF 2.0 and Academic service: Den Haag, The Netherlands, 2014.

4. Stubbs, W.; Cocklin, C. Conceptualizing a "sustainability business model". Org. Environ. 2008, 21, $103-127$. [CrossRef]

5. Schaltegger, S.; Wagner, M. Sustainable entrepreneurship and sustainability innovation. Categories and interactions. Bus. Strat. Environ. 2011, 20, 222-237. [CrossRef]

6. Pedersen, E.; Rahbek, G.; Gardetti, M.A. Introduction. J. Corp. Cit. 2015, 57, 5-10.

7. Blühdorn, I. The governance of unsustainability: Ecology and democracy after the postdemocratic turn. Environ. Polit. 2013, 22, 16-36. [CrossRef]

8. Bocken, N.M.P.; Short, S.W.; Rana, P.; Evans, S. A literature and practice review to develop sustainable business model archetypes. J. Clean. Prod. 2014, 65, 42-56. [CrossRef]

9. Evans, S.; Bergendahl, M.N.; Gregory, M.; Ryan, C. Towards a Sustainable Industrial System. With Recommendations for Education, Research, Industry and Policy; University of Cambridge: Cambridge, UK, 2009.

10. Grin, J.; Rotmans, J.; Schot, J. Transitions to Sustainable Development. New Directions in the Study of Long Term Transformative Change; Routledge: Oxon, UK, 2010.

11. Osterwalder, A.; Pigneur, Y. Business Model Generation. A Handbook for Visionaries, Game Changers, and Challengers; John Wiley and Sons: Hoboken, NJ, USA, 2010.

12. Hvass, K.K. Business Model Innovation through Second Hand Retailing: A Fashion Industry Case. J. Corp. Cit. 2015, 57, 11-32. [CrossRef]

13. Yunus, M.; Moingeon, B.; Lehmann-Ortega, L. Building Social Business Models: Lessons from the Grameen Experience. Long Range Plan. 2010, 43, 308-325. [CrossRef]

14. Model Behavior. 20 Business Model Innovations for Sustainability; SustainAbility: Brooklyn, NY, USA, 2014.

15. Boons, F.; Lüdeke-Freund, F. Business models for sustainable innovation: State-of-the-art and steps towards a research agenda. J. Clean. Prod. 2013, 45, 9-19. [CrossRef]

16. Rotmans, J.; Loorbach, D. Towards better understanding of transitions and their governance: A systemic and reflexive approach. In Transitions to Sustainable Development. New Directions in the Study of Long Term Transformative Change; Grin, J., Rotmans, J., Schot, J., Eds.; Routledge: London, UK, 2010.

17. Grin, J. Understanding transitions from a governance perspective. In Transitions to Sustainable Development. New Directions in the Study of Long Term Transformative Change; Grin, J., Rotmans, J., Schot, J., Eds.; Routledge: London, UK, 2010.

18. Johnson, M.W. Seizing the White Space. In Business Model Innovation for Growth and Renewal; Harvard Business School Press: Boston, MA, USA, 2010.

19. Lovins, A.B.; Lovins, L.H.; Hawken, P. A Road Map for Natural Capitalism. Available online: http:/ /www.natcap.org/images/other/HBR-RMINatCap.pdf (accessed on 19 January 2016). 
20. Tukker, A., Tischner, U., Eds.; New Business for Old Europe. Product-service Development, Competitiveness and Sustainability; Greenleaf: Sheffield, UK, 2006.

21. Hansen, E.G.; Große-Dunker, F.; Reichwald, R. Sustainability innovation Cube. A framework to evaluate sustainability-oriented innovations. Int. J. Inn Man. 2009, 13, 683-713. [CrossRef]

22. Gorissen, L.; Manshoven, S.; Vrancken, K. Tailoring business model innovation towards grand challenges: Employment of a transition management approach for the social enterprise "Reuse Centers". JGR 2014, 5, 289-311. [CrossRef]

23. Rotmans, J. In Het Oog Van De Orkaan. Nederland in Transitie; Aeneas: Boxtel, The Netherlands, 2012.

24. Loorbach, D.; van Bakel, J.C.; Whiteman, G.; Rotmans, J. Business strategies towards sustainable systems. Bus Strat. Environ. 2010, 19, 133-146. [CrossRef]

25. Nevens, F.; De Weerdt, Y.; Gorissen, L.; Berloznic, R. Transition in Research. Research in transition. When Technology Meets Sustainability; VITO NV: Antwerp, Belgium, 2013.

26. Avelino, F. Power in Transition. Empowering Discourses on SustainabilityTransitions. Ph.D. Thesis, Wöhrman Print Services, Rotterdam, The Netherlands, 2011.

27. Loorbach, D. Transition Management. New Mode of Governance for Sustainable Development. Available online: http:/ / repub.eur.nl/pub/10200 (accessed on 19 January 2016).

28. Loorbach, D.; Rotmans, J. The practice of transition management: Examples and lessons from four distinct cases. Futures 2010, 42, 237-246. [CrossRef]

29. Rotmans, J.; Loorbach, D. Complexity and Transition Management. J. Ind. Ecol. 2009, 13, 184-196. [CrossRef]

30. Avelino, F.; Rotmans, J. Power in Transition. An Interdisciplinary Framework to Study Power in Relation to Structural Change. Eur. J. Soc. Theory 2009, 12, 543-569. [CrossRef]

31. Geels, F.W. Technological Transitions and System Innovations: A Co-Evolutionairy and Socio-Technical Analysis; Edward Elgar: Cheltenham, UK, 2005.

32. Paredis, E.; Block, T. The art of coupling. In Multiple Streams and Policy Entrepreneurship in Flemish Transition Governance Processes; Policy Research Centre TRADO: Ghent, Belgium, 2013.

33. Organization for Economic Co-operation and Development (OECD). System Innovation Synthesis Report; Organization for Economic Co-operation and Development (OECD): Paris, France, 2015.

34. De Limburgse Kringloopcentra Maken de Cirkel Rond. Samen Bouwen aan een Inclusieve Circulaire Economie en een Klimaatneutraal Limburg. Available online: http:/ / www.vitoduurzaamheidsverslag2012. be/wp-content/uploads/2014/01/KringloopcentraLimb.pdf (accessed on 19 January 2016). (In Dutch).

35. i-Cleantech Flanders. The province of Limburg and its companies invest in cleantech. Press release 06/09/2013. Available online: http://www.greenville.be/new/uploads/pdf/persbericht-projecten.pdf (accessed on 22 January 2016).

36. Manshoven, S.; Vanasshe, S.; Van Dyck, S. Material Match Maker; VITO NV: Antwerp, Belgium, 2014.

37. i-Cleantech Vlaanderen. Eindrapport Haalbaarheidstudies; i-Cleantech Vlaanderen: Provincie Limburg, The Netherlands, 2014.

38. Taanman, M.; Wittmayer, J.M.; Diepenmaat, H. Monitoring on-going vision development in system change programmes. J. Chain Netw. Sci. 2012, 12, 125-136. [CrossRef]

39. Grin, J. Reflexive modernization as a governance issue, or designing and shaping re-structuration. In Reflexive Governance for Sustainable Development; Voss, J.P., Bauknecht, D., Kemp, R., Eds.; Edward Elgar Publishing: Cheltenham, UK, 2006.

40. Jones, G.; Kramar, R. CSR and the building of leadership capability. JGR 2010, 1, 250-259. [CrossRef]

41. Cash, D.; Clark, W.; Alcock, F.; Dickson, N.; Eckley, N.; Jäger, J. Salience, Credibility, Legitimacy and Boundaries: Linking Research, Assessment and Decision Making. Faculty Research Working Paper Series; John F. Kennedy School of Government, Harvard University: Harvard, MA, USA, 2002.

42. Wittmayer, J.M.; Schäpke, N. Action, research and participation: Roles of researchers in sustainability transitions. Sustain. Sci. 2014, 9, 483-496. [CrossRef]

43. Avelino, F.; Rotmans, J. A dynamic conceptualization of power for sustainability research. J. Clean. Prod. 2011, 19, 796-804. [CrossRef]

44. Hult, G.T.M. Market-focused sustainability: Market orientation plus! J. Acad. Market Sci. 2011, 39, 1-6. [CrossRef] 
45. Hult, G.T.M.; Mena, J.A.; Ferrel, O.C.; Ferrel, L. Stakeholder marketing: A definition and conceptual framework. AMS Rev. 2011, 1, 44-65. [CrossRef]

46. Raminez, E. Consumer-defined sustainably-oriented firms and factors influencing adoption. J. Bus. Res. 2013, 66, 2202-2209. [CrossRef] 